\title{
Caracterização meso e microscópica de bandas de deformação em arenitos porosos: um exemplo nas tectonossequências Paleozoica, Pré- e Sin-rifte da Bacia do Araripe, Nordeste do Brasil

\author{
Meso and microscopic characterization of deformation bands in porous sandstones: an example \\ on the Paleozoic, Pre-and Sin-rift sequences of the Araripe Basin, Northeast of Brazil
}

João Marculino de Araújo Netto ${ }^{1}$, Fernando César Alves da Silva ${ }^{1}$ e Emanuel Ferraz Jardim de Sá ${ }^{1}$

${ }^{1}$ Programa de Pós-Graduação em Geodinâmica e Geofísica - PPGG - Universidade Federal do Rio Grande do Norte - UFRN, Caixa postal 1639 - Campus Universitário, CEP 59078-970, Natal, RN, BR (jota_ex2@hotmail.com), (fernando@geologia.ufrn.br), (emanuel@ccet.ufrn.br)

Recebido em 12 de setembro de 2011; aceito em 08 de março de 2012

\begin{abstract}
Resumo
Bandas de deformação são estreitos volumes tabulares desenvolvidos em arenitos porosos. Apesar de produzidas em condições de deformação frágil, internamente podem apresentar gradiente de deslocamento contínuo. Quando o mecanismo de deformação dominante durante a nucleação dessas bandas é a cataclase granular, podem ser alteradas significativamente as propriedades originais de suas rochas hospedeiras, tais como porosidade e permeabilidade. Bandas de deformação, presentes nos arenitos pré- e sin-rifte da Bacia do Araripe, foram estudadas em meso e microescala com o intuito de classificá-las e de entender os mecanismos deformacionais envolvidos durante sua nucleação e desenvolvimento. Critérios geométrico-espaciais, cinemáticos e reológicos permitiram estabelecer as relações entre a gênese das bandas de deformação e a litificação dos arenitos protólitos. À luz desses dados, discutiu-se o impacto dessas estruturas no fluxo de fluido, na escala de reservatório. Além disso, o estudo das bandas de deformação auxiliou no entendimento da evolução geotectônica da bacia sedimentar estudada. Dessa maneira, o estudo das bandas de deformação pode subsidiar pesquisas sobre a evolução tectonossedimentar local e regional de bacias sedimentares.
\end{abstract}

Palavras-chave: Bandas de deformação; Bacia do Araripe; Cataclase granular.

\begin{abstract}
Deformation bands are narrow tabular volumes developed in porous sandstones. Although these structures are a product of brittle deformation, they may have internally a continuous displacement gradient. When granular cataclasis is the dominant deformation mechanism, the initial properties of their host rocks (i.e., porosity and permeability) can change significantly. The deformation bands in sandstones from the pre- and syn-rift of the Araripe Basin were studied in meso and microscale in order to classify them and to understand the deformation mechanisms involved during their nucleation and development. Their geometric-spatial, kinematic, and rheological criteria allowed establishing relations between the origin of deformation bands and lithification of their host rocks. Additionally, some inferences on their influence to the fluid flow in the reservoir-scale were outlined. Moreover, the study of deformation bands contributed to the understanding of the tectonic evolution of the studied basin. Accordingly, the study of deformation bands can support research on local and regional aspects of the tectonosedimentary evolution of sedimentary basins.
\end{abstract}

Keywords: Deformation bands; Araripe Basin; Granular cataclasis. 


\section{INTRODUÇÃO}

Bandas de deformação (Aydin, 1978) são estruturas planares que ocorrem comumente em arenitos porosos. Essas estreitas faixas deformacionais são capazes de modificar, localmente, as propriedades petrofísicas intrínsecas de rochas reservatório (porosidade e permeabilidade). A diminuição da porosidade e da permeabilidade das bandas de deformação, em comparação com o arenito hospedeiro, é comumente interpretada como uma barreira (Antonellini e Aydin, 1994, 1995; Holcomb et al., 2007; Faulkner et al., 2010) para a passagem ou migração de fluidos (água, óleo ou gás) no interior das bacias sedimentares, embora alguns autores (Fossen e Bale, 2007; Alves da Silva et al., 2007; Medeiros et al., 2010) minimizem tal influência.

Uma vez que as bandas de deformação não são imageadas por métodos sísmicos, trabalhos sobre a caracterização geométrico-espacial e petrofísica dessas estruturas têm sido cada vez mais publicados, com o intuito de compreender o possível impacto que produzem em arenitos reservatórios. Paralelamente, estudos acerca da evolução estrutural (mecanismos de deformação), cinemática e relação das bandas de deformação com aspectos diagenéticos, por exemplo, podem fornecer subsídio para interpretações sobre a história tectonoestrutural de determinada bacia sedimentar. Nesse contexto, a presença das bandas de deformação nas tectonossequências pré e sin-rifte da Bacia do Araripe possibilitou, por meio de análises meso e microscópicas, estudá-las, com a finalidade de contribuir para o melhor entendimento da geologia da bacia, além de especular sobre o comportamento barreira/conduto delas ao fluxo de fluidos em escala de reservatório.

\section{CONTEXTUALIZAÇÃO GEOLÓGICA}

A Bacia do Araripe é uma das maiores e mais completas bacias interiores do Nordeste brasileiro. É constituída por quatro tectonossequências principais (Ponte e Appi, 1990): Paleozoica (Formação Maurití); Prérifte (Formações Brejo Santo e Missão Velha); Sinrifte (Formação Abaiara) e Pós-rifte (Formações Rio da Batateira, Santana, Arajara e Exu). Assine (2007), com base nos trabalhos de Ponte e Appi (1990) e Assine (1992), realizou uma revisão das unidades litoestratigráficas da referida bacia, na qual, além de propor a nomenclatura Cariri para a Formação Maurití, também apresentou a divisão da Sequência Pós-rifte em dois estágios distintos: I (subsidência flexural, na qual estão incluídas as formações Barbalha e Santana) e II (soerguimento epirogênico, formações Araripina e Exu).
Essa e as demais bacias interiores vêm sendo palco de diversos estudos da equipe da Universidade Federal do Rio Grande do Norte (UFRN), enfocando seus aspectos tectonoestratigráficos e estruturais (Almeida et al., 2009; Aquino, 2009; Araújo Netto, 2009; Araújo Netto e Alves da Silva, 2009; Cardoso et al., 2009; Jardim de Sá et al., 2009; Melo e Alves da Silva, 2009; Cardoso, 2010; Costa, 2010; Araújo Netto e Alves da Silva, 2011, entre outros). O presente estudo foi desenvolvido na porção Leste da bacia (Figura 1), às vezes referida na literatura como Sub-bacia do Cariri.

As tectonossequências estudadas neste trabalho são representadas pelas Formações Maurití, Brejo Santo, Missão Velha e Abaiara. A Formação Maurití é constituída por rochas siliciclásticas, como orto e paraconglomerados, arcóseos e quartzos-arenitos médios a grossos. Comumente, possuem estratificações cruzadas tabulares (Figura 2A) e acanaladas de médio porte, com sentido de paleocorrente dominante para NW. A Formação Brejo Santo é composta por folhelhos cinza-esverdeados, argilitos avermelhados (Figura 2B) e siltitos, entre os quais ocorrem camadas decimétricas a métricas de arenitos finos a médios e delgadas lâminas de calcário argiloso, rico em ostracodes, às vezes formando bancos de ostracoditos (Assine, 1992, 2007). A Formação Missão Velha é formada por quartzos-arenitos bem selecionados e arcóseos finos a médios, brancos a avermelhados, por vezes intercalados a camadas pelíticas. Os arenitos podem exibir estratificações cruzadas tabulares de médio porte e têm como principal característica a presença de troncos de madeira silicificados (Figura 2C). A Formação Abaiara é composta por arenitos finos a médios e conglomerados intercalados a pelitos (siltitos, argilitos e folhelhos). As principais estruturas sedimentares reconhecidas são laminações plano-paralelas, estratificações cruzadas tabular e acanalada de médio porte, gretas de contração e estruturas produzidas por deformação sindeposicional, tais como: clastos argilosos parcialmente litificados (Figura 2D), fluidilização e dobras de escorregamento. Os estratos dessas formações normalmente exibem mergulhos suaves (entre 2 e $10^{\circ}$ ); contudo, podem apresentar mergulhos da ordem de $45^{\circ}$, quando fortemente basculados por falhas normais.

A Bacia do Araripe está tectonicamente compartimentada por sistemas de falhas normais NE-SW, delimitando horsts e grabens e, subordinadamente, transcorrentes NNE-SSW e E-W, respectivamente, dextrais e sinistrais. As sequências areníticas estudadas exibem, com certa frequência, bandas de deformações relacionadas a zonas de danos de falhas normais, transcorrentes, as quais geralmente estão dispostas em pares conjugados (dextrais e sinistrais), e mais raramente falhas inversas. 


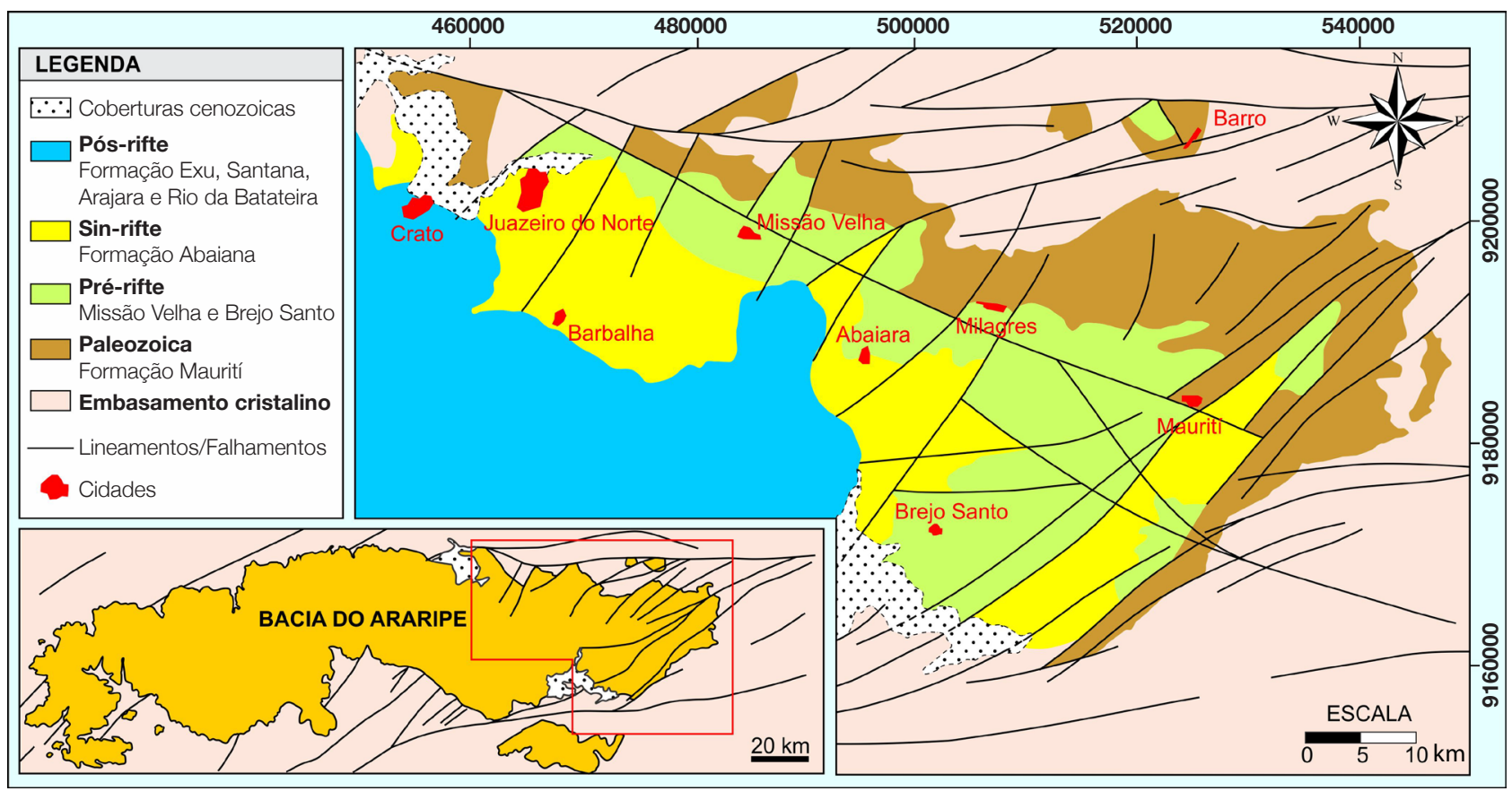

Figura 1. Mapa geológico simplificado da porção Leste da Bacia do Araripe. Estão representadas no mapa as tectonossequências Paleozoica, Pré-, Sin- e Pós-rifte. Baseado em Ponte e Appi (1990) e no Projeto Bacias Interiores do Nordeste Brasileiro (UFRN/PETROBRAS/FUNPEC).

\section{BANDAS DE DEFORMAÇÃO: FUNDAMENTAÇÃO TEÓRICA}

Devido à escassez desse tema na literatura nacional, a seguir será realizada uma breve explanação sobre os tipos de bandas de deformação, mecanismos deformacionais envolvidos na sua formação e seu arranjo geométrico-espacial.

A deformação frágil em rochas de baixa porosidade ocorre primariamente por fraturamentos, gerando-se os principais tipos de estruturas frágeis (juntas e falhas). Entretanto, quando rochas de alta porosidade são submetidas à deformação, a tensão se concentra em estreitas zonas, ou faixas, produzindo as denominadas 'bandas de deformação'.

A distinção entre bandas de deformação, juntas de distensão e falhas está relacionada ao caráter deformacional peculiar que cada uma dessas estruturas apresenta. Juntas de distensão representam simples planos de partição sem deslocamento ou rejeito (salvo quando são híbridas); falhas (e fraturas cisalhantes) são planos com deslocamento relativo de blocos; enquanto as bandas de deformação são volumes tabulares que possuem gradiente de deslocamento interno com caráter contínuo (Antonellini et al., 1994; Draganits et al., 2005, Figura 3), comportando-se analogamente a zonas de cisalhamento dúcteis, embora produzidas nas mesmas condições externas de deformação frágil.
A notável associação entre bandas de deformação e arenitos porosos está intrinsecamente relacionada ao comportamento mecânico destes, quando submetidos a esforços (Antonellini e Pollard, 1995; Menéndez et al., 1996; Mair et al., 2000). O desenvolvimento das bandas de deformação envolve diversos processos de efetiva interação granular, nos quais podem se incluir rotação/ reorientação, deslizamento friccional, esmagamento e indentação granular. Tais processos ocorrem - e são favorecidos - quando se aplica tensão em materiais granulares (arenosos), com quantidades significativas de espaços entre seus grãos (porosidade intergranular). Dessa forma, arenitos porosos são rochas que apresentam condições petrofísicas e geomecânicas mais adequadas a nuclear e desenvolver bandas de deformação.

\section{Classificação e aspectos reológicos}

Embora haja diversos critérios de classificação das bandas de deformação (Antonellini et al., 1994; Mollema e Antonellini, 1996; Aydin et al., 2006; Fossen et al., 2007), neste trabalho procurou-se simplificar, fazendo-se uso somente de classificações hierárquica, cinemática e reológica.

Hierarquicamente, as bandas de deformação ocorrem tanto individuais (denominadas singles) quanto em 

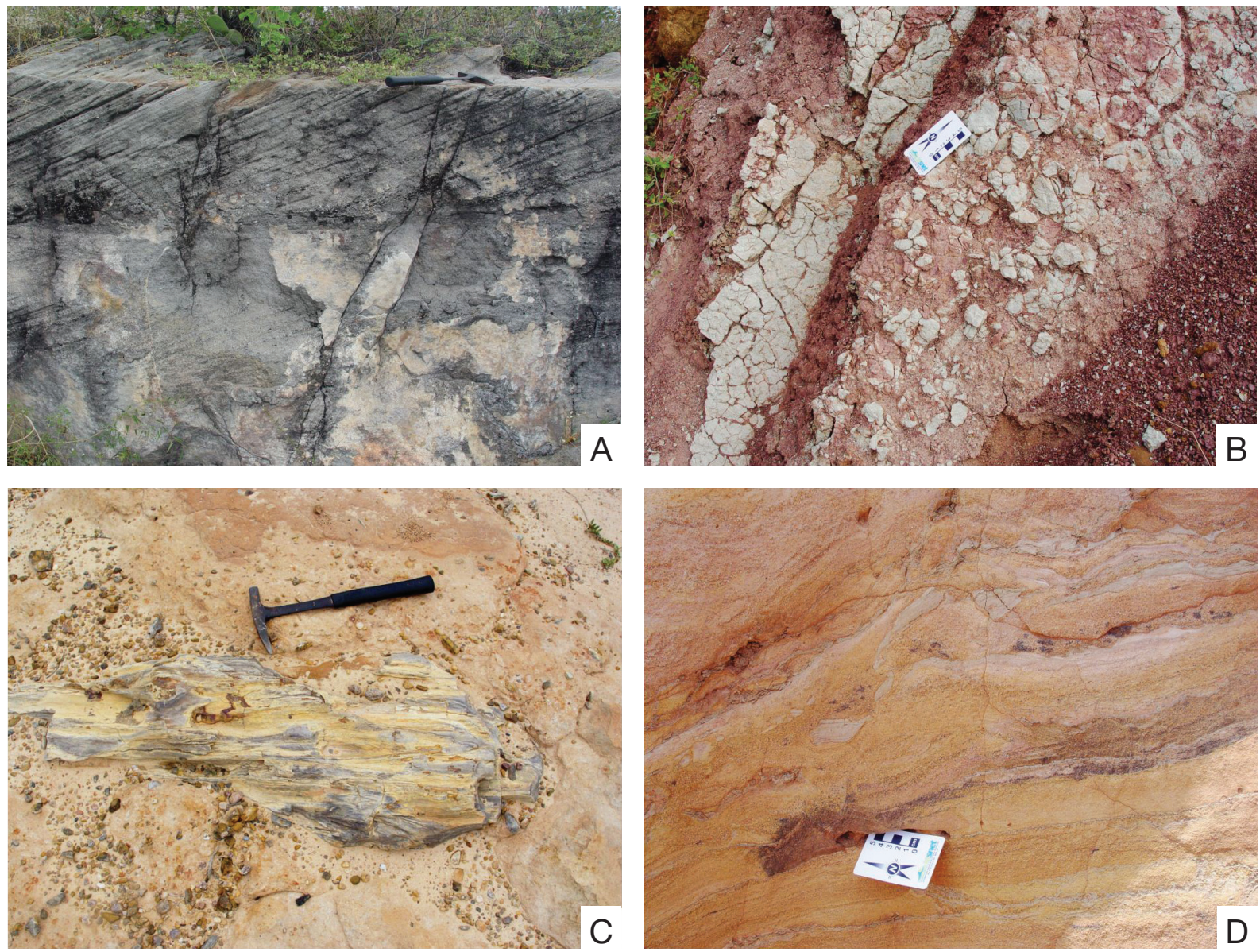

Figura 2. Aspectos de campo das principais formações estudadas. (A) Formação Maurití (arenitos médios com estratificação cruzada tabular de médio porte); (B) formação Brejo Santo (folhelhos cinza-esverdeados e argilitos avermelhados); (C) tronco de madeira silicificado em arenito fino a médio da Formação Missão Velha; (D) clastos argilosos deformados em arenito médio da Formação Abaiara (reforçando deformação sindeposicional).
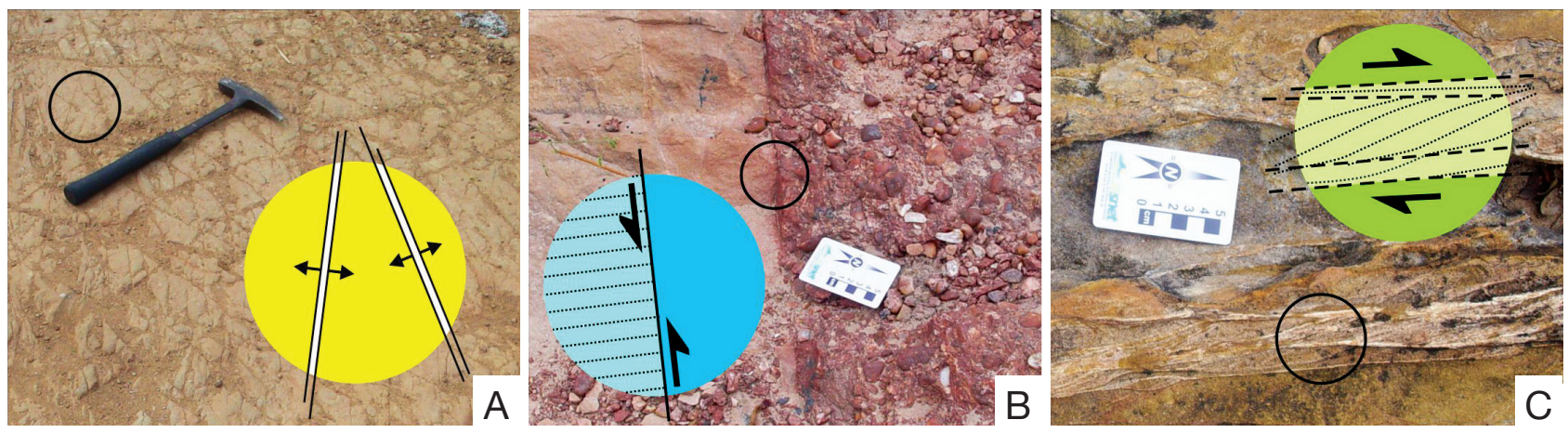

Figura 3. llustração do caráter deformacional descontínuo de estruturas frágeis. (A) Planos de partição sem rejeito (juntas de distensão no arenito Missão Velha); (B) superfícies bem definidas com deslocamento relativo de blocos (falhas/fraturas cisalhantes, exemplo na Formação Mauritî). Ao contrário das anteriores, (C) ilustra um volume tabular com deslocamento interno contínuo ("zonas de cisalhamento"; em arenitos porosos, essas estruturas são representadas por bandas de deformação, desenvolvidas no arenito Abaiara). 
aglomerados (denominados clusters), como mostradas na Figura 4. Singles apresentam espessura variando de alguns milímetros a poucos centímetros (inferiores a $2,0 \mathrm{~cm}$ ) e, mesmo atingindo alguns metros de comprimento, têm rejeitos milimétricos (raramente centimétricos). Em contraste, os clusters são mais espessos (entre 3,0 e 10,0 cm) e possuem rejeitos maiores, pois acumulam o rejeito de cada single que o compõe. Algumas bandas de deformação podem apresentar, em sua porção interna, superfícies de deslizamento bem definidas, inclusive com lineações de estria. A evolução dessas superfícies, com progressivo aumento (cumulativo) de rejeito, pode levar à geração de falhas, com rejeitos bem mais expressivos (Hesthammer et al., 2000).

Do ponto de vista cinemático, as bandas de deformação são classificadas em três end-members: bandas dilatacionais (dilation bands), contração (compaction bands) e cisalhantes (shear bands). Esses três tipos principais também podem se combinar formando tipos híbridos (Aydin et al., 2006). Em tese, as bandas dilatacionais e contracionais estão associadas somente à deformação por cisalhamento puro com variação volumétrica, respectivamente, aumento e diminuição de volume, enquanto que as cisalhantes estão relacionadas à deformação por cisalhamento simples.

Quanto ao comportamento reológico, as bandas de deformação são referidas como: não cataclásticas (disaggregation bands, de Fossen et al., 2007, pela falta de nomenclatura mais apropriada, adotou-se os termos hidrodúctil ou hidroplástica) e cataclásticas (cataclastic bands). As bandas não cataclásticas são caracterizadas por apresentarem pouca ou nenhuma evidência de quebramento granular, nesse caso, o mecanismo de deformação atuante é o fluxo granular (ou fluxo particular, no qual os grãos rotacionam e deslizam uns contra os outros sem se quebrar). Este mecanismo deformacional é típico de materiais pobre ou parcialmente consolidados.

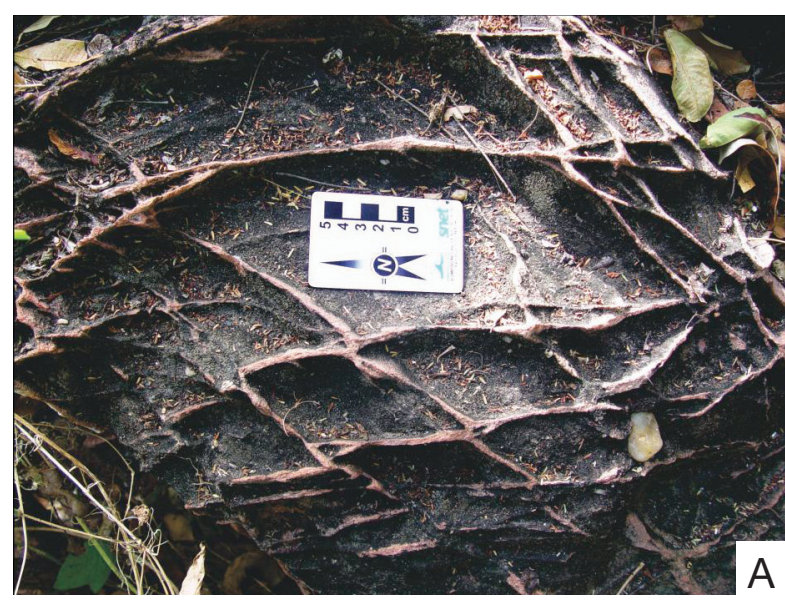

Figura 4. Bandas de deformação. (A) Individuais singles; (B) agrupamento de bandas de deformação formando um cluster, em arenitos da Formação Missão Velha.

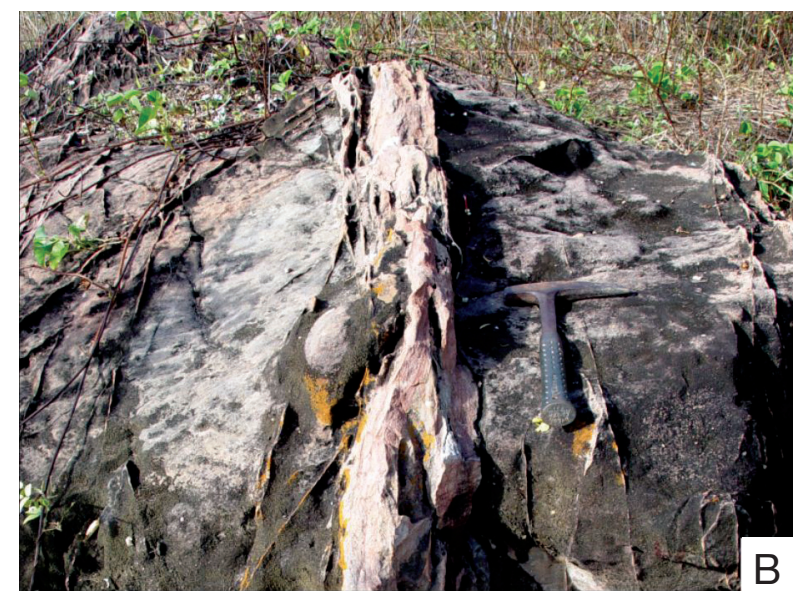

A deformação, no contexto de arenitos totalmente litificados, produz bandas cataclásticas, em que o mecanismo de deformação dominante é o fluxo cataclástico, no qual está diretamente relacionado ao mecanismo de cataclase granular. Este, por sua vez, ocorre quando a interação granular é suficiente para promover o quebramento dos grãos, produzindo-se matriz cataclástica. Dependendo da intensidade da deformação, as bandas cataclásticas podem apresentar zonação microscópica (Figura 5) relacionada à variação no grau de cataclase, identificada por Aydin (1978) em núcleo (ou zona interna), zona externa e zona não deformada (ou rocha hospedeira). Nesse arranjo, o núcleo da banda constitui-se praticamente por matriz cataclástica (ou tectônica), a qual é produzida pelo intenso mecanismo de cataclase granular (esmagamento, moagem e cominuição dos grãos). Notavelmente, a quantidade de grãos cominuídos diminui do núcleo para a zona externa, indicando que a deformação também diminua nesse sentido.

\section{Disposição geométrico-espacial}

Geometricamente, as bandas de deformação podem se desenvolver em pares conjugados e/ou apresentando-se como diversas estruturas planares, orientadas em ângulos específicos, segundo uma zona de cisalhamento principal, a exemplo das fraturas cisalhantes de Riedel (sendo assim, bandas em posições Y, R, R', P e X). Algumas vezes, $\mathrm{o}$ arranjo geométrico-espacial das bandas de deformação pode ser bastante complexo, principalmente quando estas ocorrem em zona de dano de falhas (fault damage zone, Shipton e Cowie, 2003; Kim et al., 2003, 2004), que envolve uma falha principal e contém diversas estruturas subsidiárias (juntas, fraturas cisalhantes etc.). 


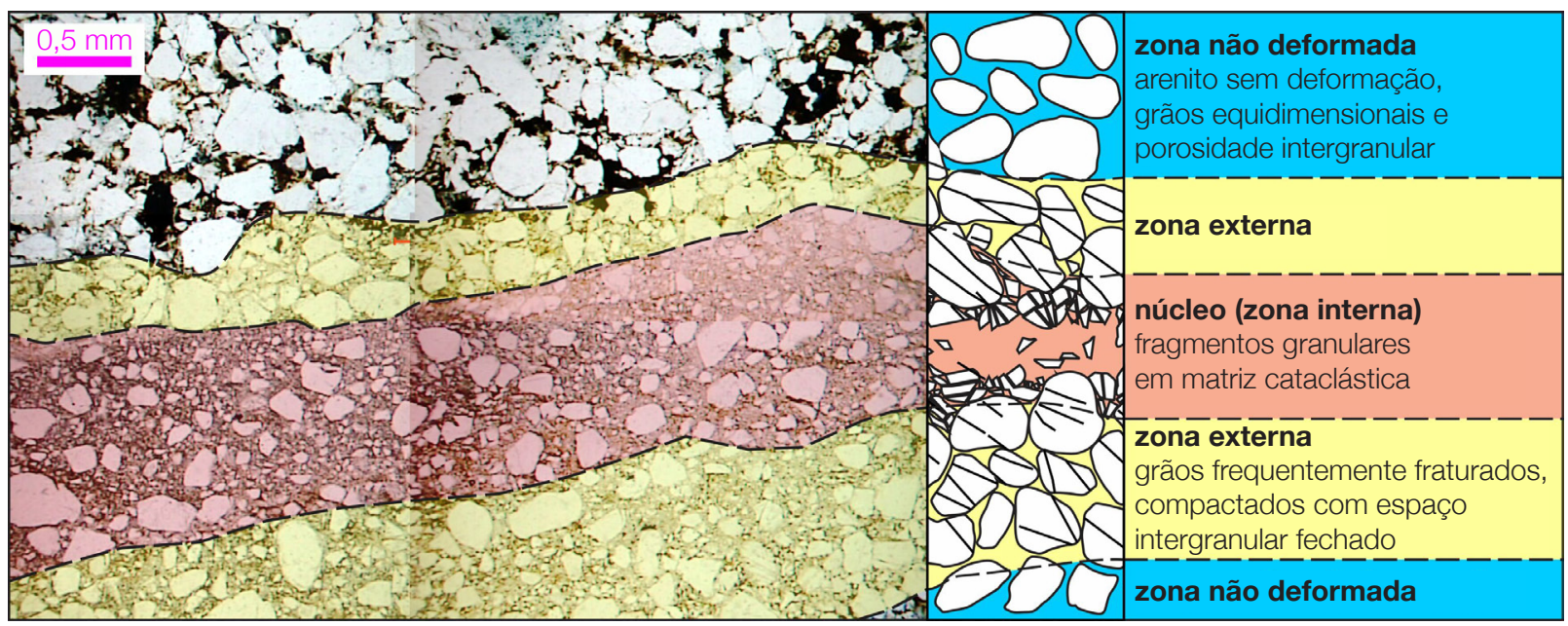

Figura 5. Fotomicrografia e representação esquemática da zonação microscópica de uma banda de deformação cataclástica, desenvolvida em arenito da Formação Maurití (UTM 534533-9182661).

\section{METODOLOGIA}

A abordagem das bandas de deformação da área de estudo foi feita em duas etapas: (i) macroscópica, referente ao trabalho em afloramentos, nos quais a disposição geométrica e, quando possível, cinemática, dessas estruturas foi observada; e (ii) microscópica, na qual buscou-se evidências sobre os mecanismos de deformação (comportamento reológico) atuantes na formação das bandas de deformação, relação textural entre suas porções internas e externas, bem como sua cinemática. A relação geométrico-estrutural, mecanismo de deformação e com o estágio de litificação da rocha também foram estudadas.

\section{ANÁLISE MESOSCÓPICA DAS BANDAS DE DEFORMAÇÃO}

Esta parte do estudo foi desenvolvida em afloramentos de arenitos das Formações Maurití, Missão Velha e Abaiara da Bacia do Araripe, que representam, respectivamente, suas tectonossequências Paleozoica, Pré-rifte e Sin-rifte. Ressalta-se que a Formação Brejo Santo foi excluída deste estudo por apresentar litologias essencialmente pelíticas. Em escala mais regional, essas estruturas estão associadas a falhamentos normais e transcorrentes que compõem o arranjo estrutural da bacia em questão.

\section{Hierarquia}

Nos afloramentos estudados, as bandas de deformação podem ocorrer sob a forma de faixas individuais ( $\sin$ gles) ou clusters. As bandas individuais são comumente retilíneas e descontínuas, com espessura variando de $1,5 \mathrm{~mm}$ a $3,0 \mathrm{~cm}$ (excepcionalmente) e podendo não ultrapassar poucos metros de comprimento. Os clusters podem ser retilíneos, curvos ou anastomosados, com 10 a $20 \mathrm{~cm}$ de espessura, e podem atingir vários metros de comprimento. Foram observados rejeitos milimétricos (quando single) a decimétricos (quando cluster).

\section{Análise estrutural}

As macrofeições diagnósticas de cisalhamento das bandas de deformação são o deslocamento de marcadores (Figura 6A, nem sempre de fácil visualização, quando se trata de bandas simples, devido aos rejeitos muito pequenos), as superfícies de deslizamento (Figura 6B) e as estruturas "tipo $\mathrm{S} / \mathrm{C}$ " (referidas como estruturas análogas a zonas de cisalhamento miloníticas, Figura 6C), as quais também podem apresentar estrias de deslizamento (Figura 6D). Esse tipo de arranjo "S/C", encontrado nos clusters, ainda é pouco difundido na literatura alusiva às bandas de deformação e pode, alternativamente, ser considerado como a combinação geométrica entre estrutura cisalhante principal $(\mathrm{Y})$ e sintética secundária $(\mathrm{P})$ do arranjo de Riedel e, nesse caso, formaria uma estrutura "P/Y" e não "S/C". Embora a distinção, a caracterização ou a gênese dessas estruturas não tenham sido objetivos deste estudo, o encurvamento das bandas $\mathrm{S}$ (ou P), tendendo a um paralelismo com C (ou Y) levou-se a preferir a essa disposição como análoga a "S/C", desenvolvidas em cisalhamento dúctil. A discussão desse assunto será abordada em outro artigo.

A disposição geométrico-espacial das bandas de deformação analisadas permitiu separá-las em três grandes grupos principais: NE-SW; NNE-SSW e E-W 

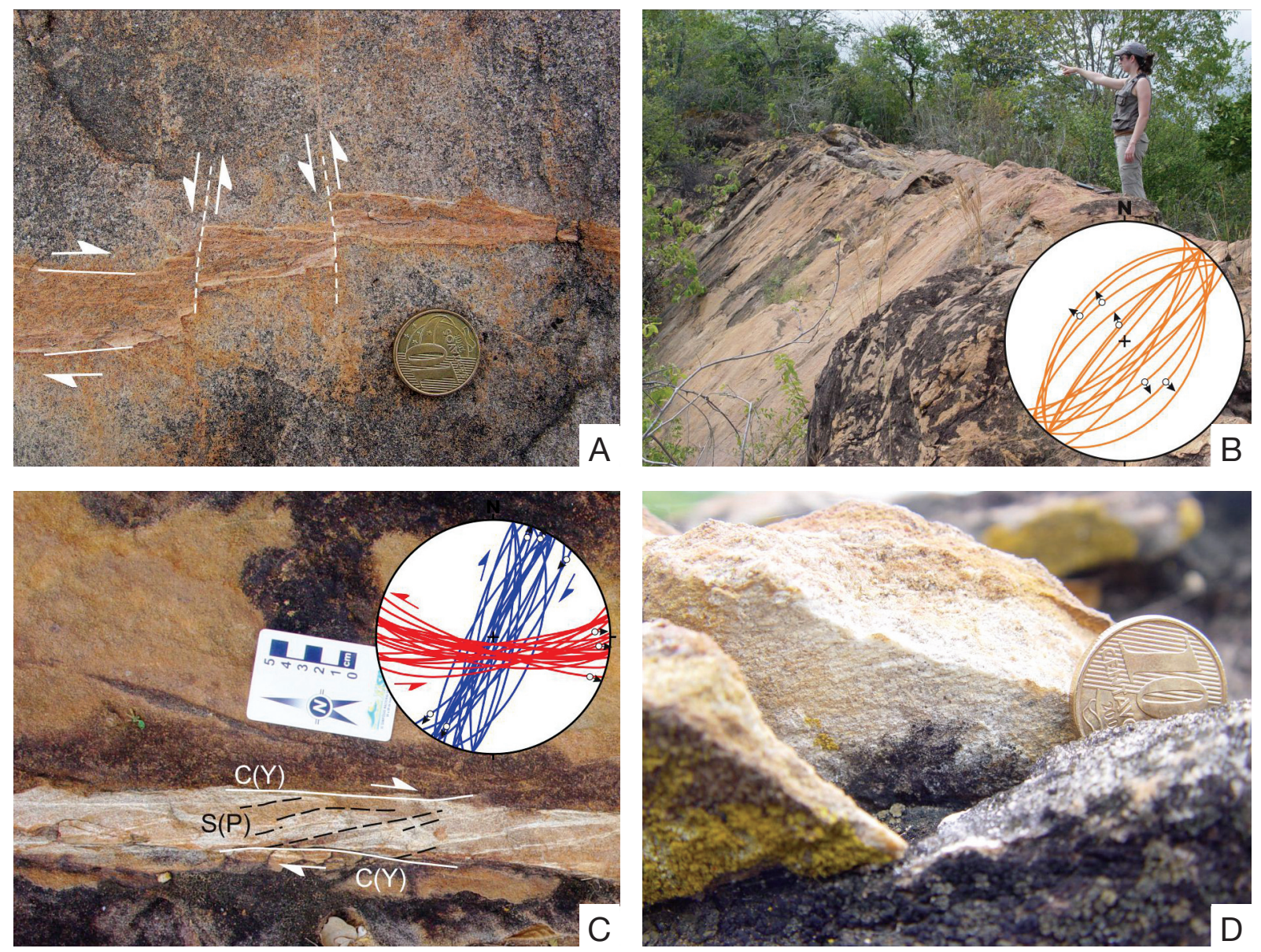

Figura 6. Aspectos mesoscópicos e orientação espacial das bandas de deformação da área estudada. (A) Bandas de deformação singles deslocando cluster de banda de deformação na Formação Maurití; (B) superfície de deslizamento (apresenta estria de alto rake, indicando movimentação vertical); (C) cluster com geometria análoga a estruturas "S/C" ("ou P/Y") exibindo (D) estria de baixo rake, evidenciando transcorrência sinistral. Os arenitos mostrados em B, C e D pertencem à Formação Abaiara.

(estereogramas). As bandas NE-SW apresentam caimento variando entre 45 e $60^{\circ}$, exibem movimento normal e estão comumente associadas à zona de dano de falhas de mesma cinemática. Essa zona encontra-se em torno de falhas, sendo caracterizada pelo aumento significativo na quantidade de bandas de deformação. As bandas NNE-SSW e E-W apresentam mergulhos fortes (da ordem de $70^{\circ}$ ), por vezes subverticais, e podem ocorrer sob a forma de pares conjugados transcorrentes, respectivamente, dextrais e sinistrais.

\section{ANÁLISE MICROSCÓPICA DAS BANDAS DE DEFORMAÇÃO}

Esta etapa do trabalho foi feita por meio de seções delgadas, confeccionadas a partir de amostradas orientadas.
A análise consistiu na caracterização de aspectos composicionais, texturais (orientação dos grãos e grau de compactação) e deformacionais (microfraturamentos, cominuição granular, matriz cataclástica e deslocamentos relativos). Desses aspectos, os deformacionais são os mais relevantes para classificar as bandas de deformação, tanto em critérios cinemáticos (dilatação, contração ou cisalhamento) quanto em reológicos (ausência ou presença de cataclase).

\section{Petrografia}

Os arenitos estudados (Maurití, Missão Velha e Abaiara) podem ser classificados, do ponto de vista petrográfico, como arenitos quartzosos médios, bem selecionados e com considerável porosidade intergranular (Figura 7A). Além dos grãos de quartzo, foi possível identificar a 

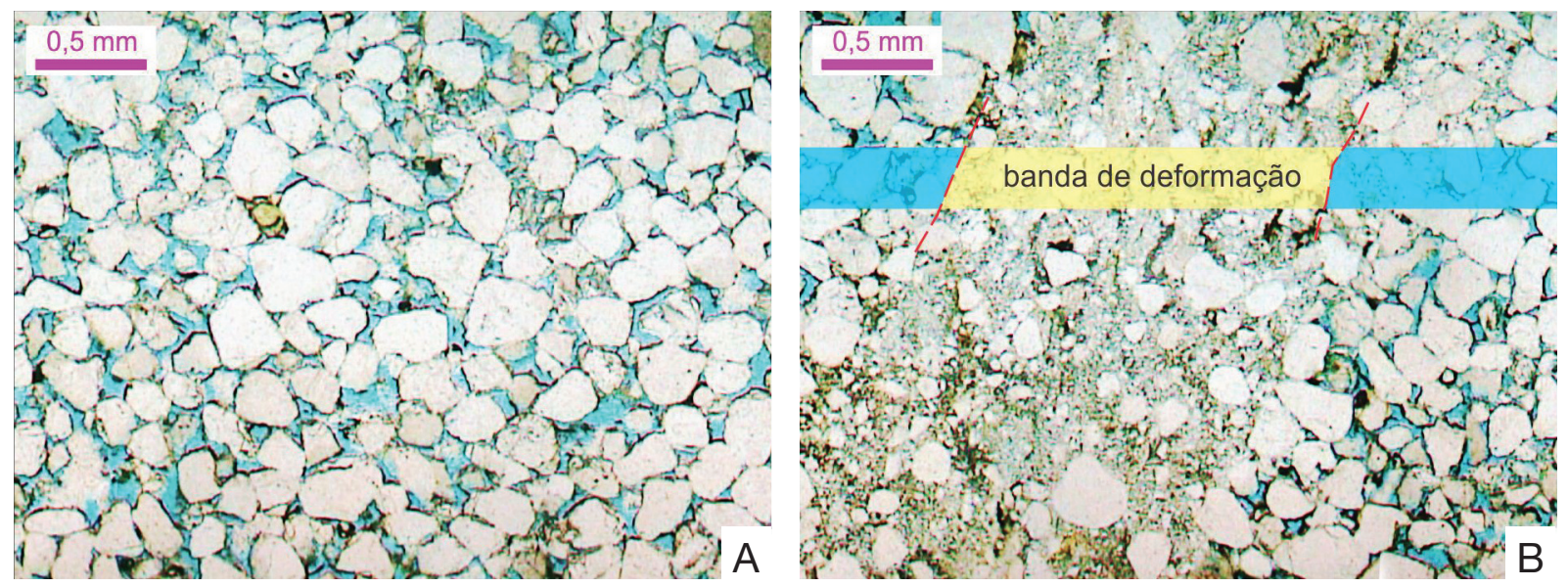

Figura 7. Fotomicrografias mostrando os aspectos petrográficos e texturais: (A) do arenito da Formação Abaiara (bem selecionado com aproximadamente $30 \%$ de porosidade) com suas propriedades originais; (B) cortado por banda de deformação cataclástica. (UTM 527967-9181181).

presença de dois tipos distintos de matriz, um de caráter deposicional e outro de caráter tectônico. A matriz deposicional, quando presente, perfaz menos de $5 \%$ da composição modal das lâminas observadas, podendo ser encontrada tanto dispersa quanto ligeiramente alinhada (marcando possíveis estratificações sedimentares). A matriz tectônica, ou cataclástica, é composta por pequenos fragmentos (de grãos) inequidimensionais e angulosos (a subangulosos), formados devido ao mecanismo de cataclase granular (que envolve rotação, deslizamento friccional, esmagamento e indentação). Pela matriz tectônica ser produzida exclusivamente pela deformação cataclástica, sua ocorrência é totalmente restrita à área da banda de deformação em seção delgada (Figura 7B).

Apesar de o mecanismo genético da matriz tectônica ser a cataclase granular, o termo gouge ("farinha de rocha") não se aplica ao contexto das bandas de deformação, uma vez que é relativo a um material incoeso produzido por deformação cataclástica em zonas de falha. Portanto, no caso das bandas de deformação, a matriz cataclástica comporta-se, pelo menos em tese, como um material (relativamente) coeso, que permite gradiente de deslocamento interno contínuo. Sendo assim, evitou-se o termo gouge na descrição da matriz cataclástica.

Os aspectos texturais considerados neste trabalho são referentes a duas porções importantes das seções delgadas: zona não deformada, que representa a rocha hospedeira; e a deformada, que é a própria banda de deformação, compartimentada em zonas externa e núcleo (ou zona interna). A zona não deformada apresenta granulometria de areia fina à grossa, variando entre 0,35 e $0,50 \mathrm{~mm}$, com porosidade média de $14 \%$. Na zona externa, o tamanho dos fragmentos pode variar entre 0,25 a $0,15 \mathrm{~mm}$, ou seja, areia fina a muito fina com porosidade inferior a 5\%; por fim, o núcleo da banda de deformação é constituído essencialmente por matriz cataclástica, formando-se uma massa muito fina aparentemente sem porosidade. Contudo, apesar dessa zonação microscópica estar bem definida em várias bandas de deformação, nem sempre é constante, podendo, em alguns casos, alguma zona estar ausente, como, por exemplo, a externa.

Analisando-se um perfil transversal à banda de deformação, é possível observar que há uma relação notável entre grau de cataclase, granulometria e porosidade em sua zona externa e núcleo, que difere totalmente da encontrada na zona não deformada ou rocha hospedeira (Figura 8). Essa relação pode ser estabelecida da seguinte maneira: a intensa deformação cataclástica submetida aos grãos causa quebramentos e moagem destes, reduzindo-se, efetivamente, a granulometria (podendo, inclusive, produzir matriz cataclástica); a redução granulométrica acarreta a compactação do arcabouço sedimentar que resulta em fechamento do espaço intergranular, reduzindo-se assim a porosidade inicial do arenito deformado.

A estimativa do comportamento barreira-conduto dessas bandas de deformação pode ser estabelecida por meio da relação da largura da zona externa (Lze) ao núcleo cataclástico em relação àquela da banda de deformação (Lbd) em seção delgada. Essa relação, denominada $\mathrm{Fa}$, foi estabelecida inicialmente por Cello et al. (2001), baseado no trabalho de Caine et al. (1996), para zonas de falhas em afloramento, que posteriormente foi utilizada por Alves da Silva et al. (2005), para bandas de deformação. Nesse contexto, medições nas bandas de deformação da área de estudo (Figura 9) foram realizadas, com o intuito de discriminar o possível comportamento hidrodinâmico dessas estruturas. A análise permitiu identificar que as bandas de deformação 


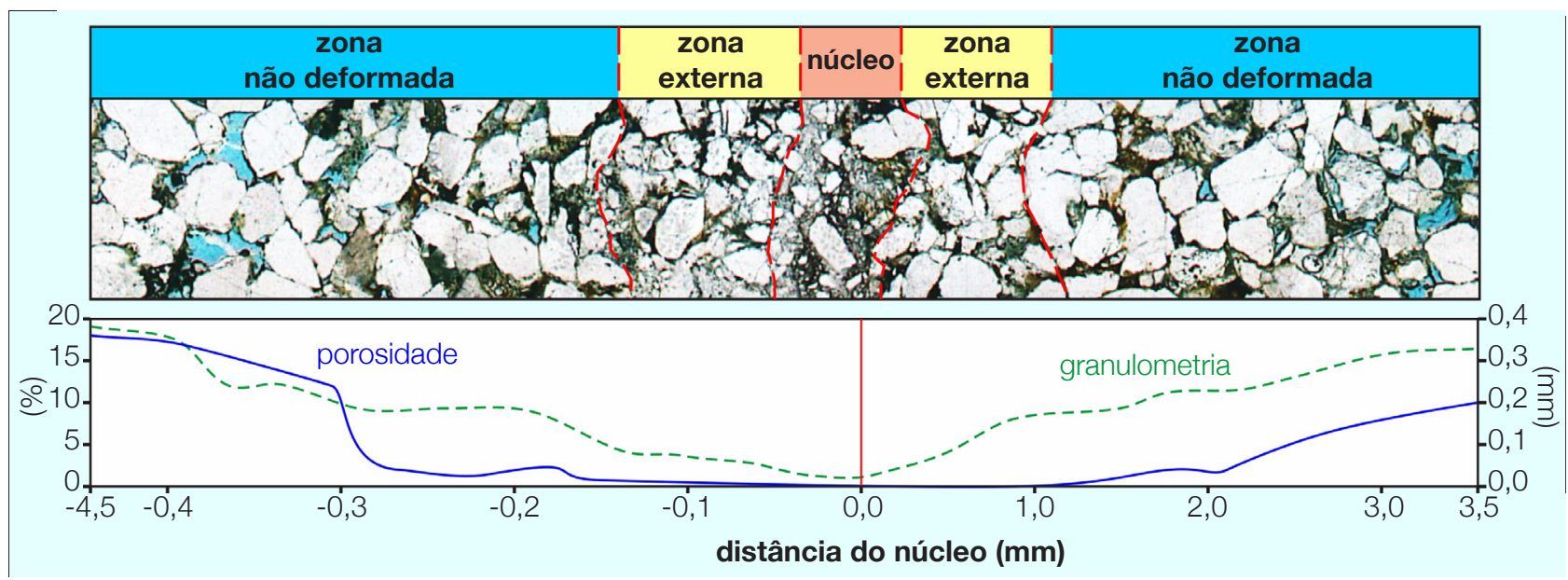

Figura 8. Relações gráficas entre cataclase, granulometria e porosidade ao longo de um perfil perpendicular à banda de deformação em arenito da Formação Maurití. A fotomicrografia mostra as zonas não deformada, externa e o núcleo; o gráfico ilustra as curvas da porosidade (\%) e de granulometria $(\mathrm{mm})$ em relação à distância do núcleo da banda. Note que, tanto granulometria quanto porosidade, decrescem no sentido do núcleo cataclástico (UTM 528258-9175510).
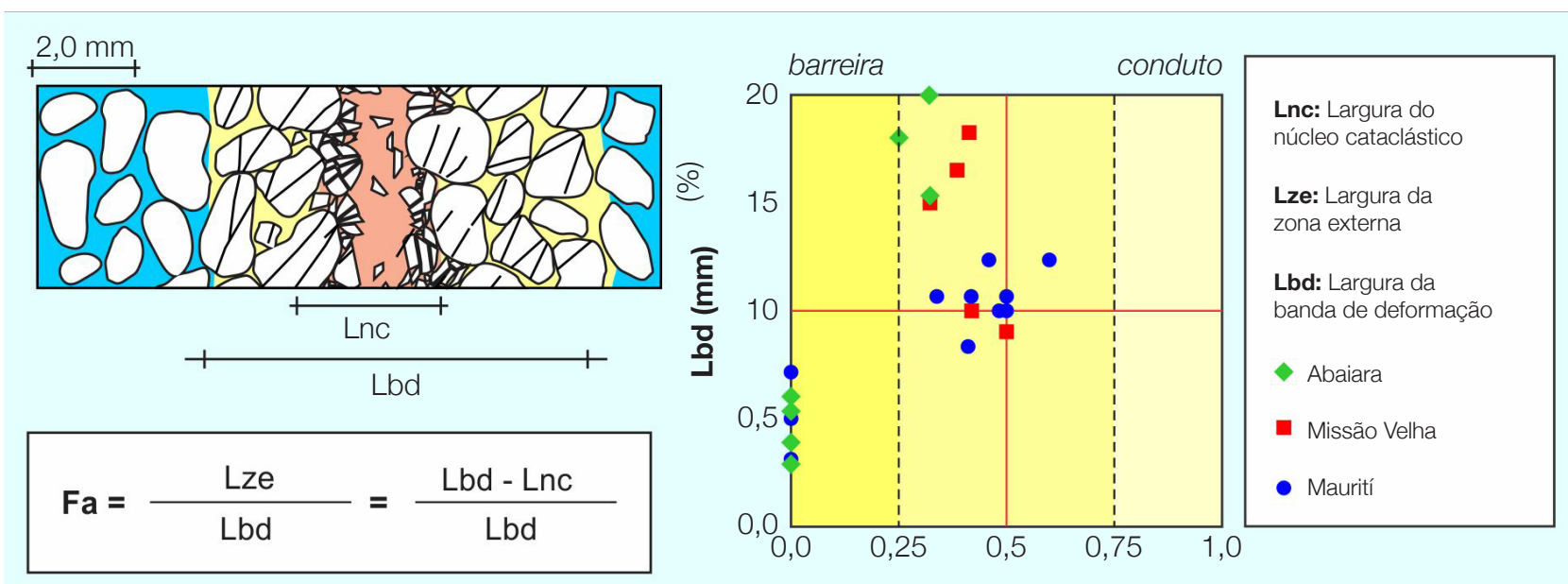

Figura 9. Análise semiquantitativa sobre o comportamento conduto/barreira das bandas de deformação, por meio do índice Fa (Cello et al., 2001). Para estabelecer a relação gráfica, é necessário conhecer os parâmetros: largura do núcleo cataclástico (Lnc), largura da zona externa (Lze) e largura da banda de deformação (Lbd) em seção delgada.

das Formações Maurití e Missão Velha têm, estatisticamente, um caráter barreira a barreira-conduto combinado, pois apresentam quantidade de matriz cataclástica, em relação à largura total da banda, bastante variável. Nesse caso, o impacto ao fluxo de fluidos pode depender de outros fatores, tais como a cimentação. As bandas de deformação dos arenitos da Formação Abaiara são enquadradas no campo 'barreira', pois a maioria de suas estruturas apresenta quantidade considerável de matriz cataclástica, constituindo, por vezes, completamente a largura total da banda de deformação em seção delgada. Dessa maneira, comparativamente, as bandas cataclásticas da Formação Abaiara apresentam, por esse parâmetro, condições mais favoráveis a compartimentar rochas reservatório do que as bandas das duas outras formações citadas.

\section{Microtectônica}

As principais microestruturas (Figura 10A) observadas nas bandas de deformação são fraturas intra 

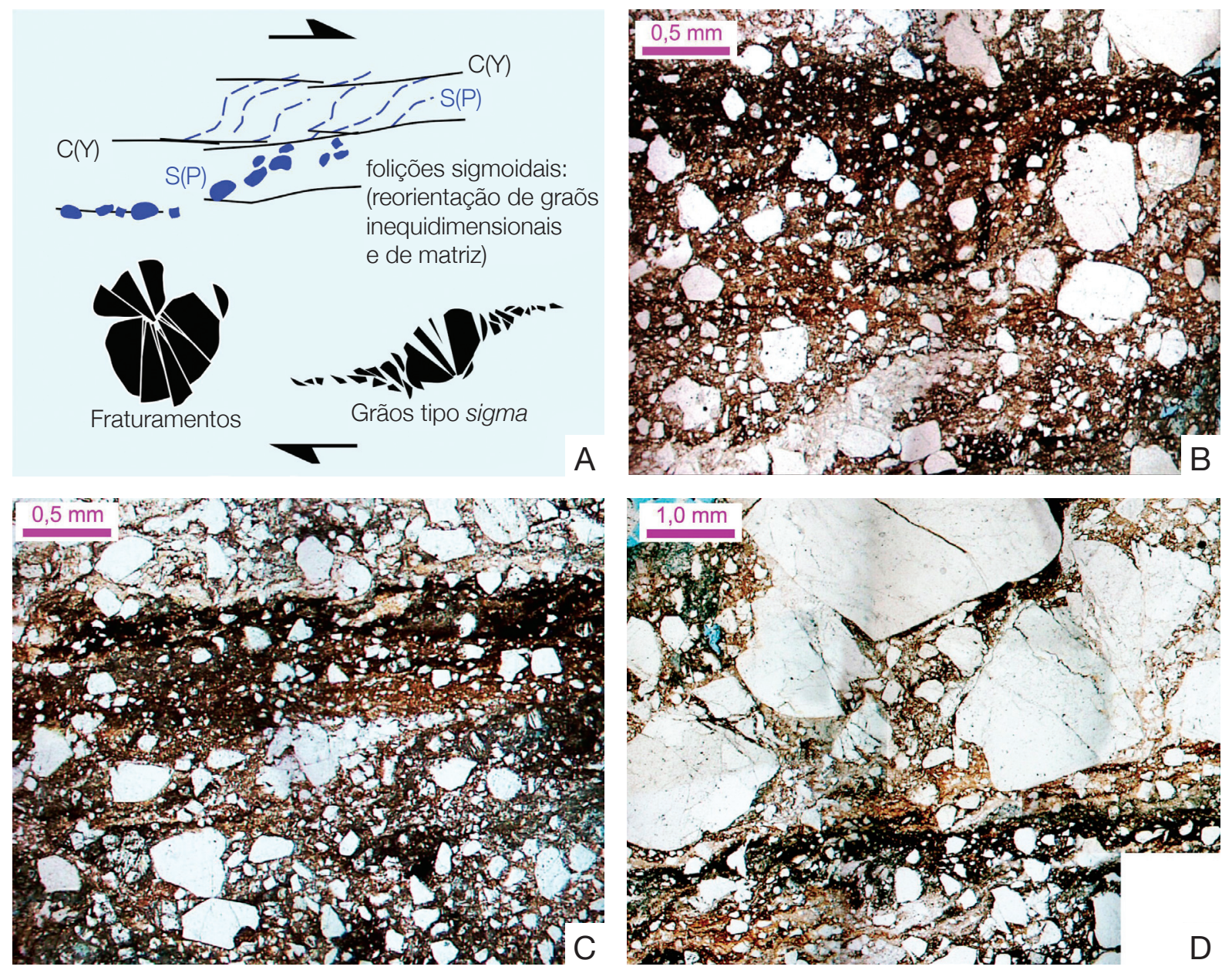

Figura 10. Ilustração de critérios cinemáticos em bandas de deformação da área estudada. (A) Representação esquemática para cisalhamento com topo para a direita; (B) microfoliação tectônica (fabric oblíquo), marcada pela reorientação de fragmentos de grãos inequidimensionais e da própria matriz cataclástica; (C) grão tipo "sigma" (centro da foto) em núcleo cataclástico, notar as "caudas de concentração de fragmentos" indicando cinemática dextral; (D) correlação cinemática entre fabric oblíquo (na matriz cataclástica) e fraturamentos dos grãos, podendo indicar deformação progressiva (UTM 523928-9206050).

e transgranulares e o deslocamento/reorientação de grãos (ou fragmentos deles) na matriz cataclástica. Desse modo, as bandas de deformação exibem, na matriz cataclástica, feições indicativas de cinemática, como microfoliações tectônicas (marcadas pelo alinhamento de fragmentos granulares inequidimensionais, Figura 10B), grãos tipo sigma (Figura 10C) e deslocamento dos mesmos ao longo de fraturas intergranulares. A foliação tectônica corresponde a um fabric oblíquo (sigmoidal) presente nas porções mais cominuídas do núcleo das bandas de deformação analisadas. Este $f a$ bric também pode ser correlacionado a um arranjo "S/C" (ou "P/Y"), correspondendo, por analogia geométrica, a uma microfoliação tectônica dúctil, que também não foi objeto deste estudo. No entanto, sua presença indica que essas bandas de deformação foram desenvolvidas por cisalhamento (simples). Os grãos tipo sigma geralmente são de quartzo, dispersos na matriz cataclástica, a qual apresenta porções intensamente fragmentadas, a ponto de, às vezes, exibir/formar uma cauda de concentração de fragmentos (visualmente semelhante a caudas de recristalização), que acompanha o movimento no núcleo da banda de deformação.

A análise das seções delgadas revela que o comportamento reológico das bandas de deformação estudadas é relacionado ao processo de cataclase granular. Isso permite inferir que essas bandas de deformação foram desenvolvidas quando os arenitos hospedeiros estavam em estágio de completa (ou quase) litificação. Entretanto, em algumas bandas analisadas, a coexistência de fraturamento e foliação tectônica (fabric oblíquo), exibindo cinemática idêntica (Figura 10D), indica 
que elas podem ter experimentado condições de deformação progressiva, iniciadas em período pré- ou sin-litificação e prosseguindo até a completa litificação dos arenitos - estudos mais detalhados, entretanto, seriam necessários para comprovar essa ideia.

\section{IMPLICAÇÃO NA EXPLORAÇÃO DE FLUIDOS}

Os arenitos podem ser excelentes rochas reservatórios de água e hidrocarbonetos, quando possuem interstícios capazes de armazenar e transmitir quantidades significativas de fluidos, ou seja, apresentem boas porosidade e permeabilidade. Porém, essas mesmas características petrofísicas também favorecem o desenvolvimento das bandas de deformação, as quais podem afetar diretamente a porosidade original dessas rochas, e, consequentemente, os impactos no fluxo de fluidos.

Apesar de as bandas de deformação serem estruturas relativamente finas com rejeito e comprimento reduzidos, a disposição geométrico-espacial, os mecanismos envolvidos na sua formação, bem como sua relação temporal com processos diagenéticos/litificação podem influenciar significativamente as propriedades porosas originais dos arenitos. Dessa maneira, a presença de bandas de deformação cataclásticas pode atuar como selante ou compartimentar reservatórios (de hidrocarbonetos ou aquíferos), gerando porções com propriedades permoporosas notavelmente menores que o arenito hospedeiro.

Devido ao fato de que as bandas de deformação são estruturas "não imageadas" em levantamentos sísmicos (e possivelmente até em alguns perfis de poço), devido a seus rejeitos e espessura reduzidos, identificar e caracterizar as zonas de bandas de deformação em arenitos porosos análogos aos reservatórios podem ajudar na prospecção e perfuração de poços (hidrocarbonetos ou água subterrânea), caracterizando-se possíveis reservatórios compartimentados (Figura 11). Ressalta-se que a característica selante somente pode ser atribuída às bandas de deformação com caráter reológico essencialmente cataclástico, pois estas apresentam matriz tectônica capaz de reduzir, de modo efetivo (embora localmente), as características petrofísicas de arenitos porosos.

\section{DISCUSSÃO E CONCLUSÕES}

A análise meso e microscópica das bandas de deformação estudadas permitiu classificá-las, do ponto de vista cinemático e reológico, como cisalhantes e cataclásticas. Os critérios cinemáticos permitiram associar essas
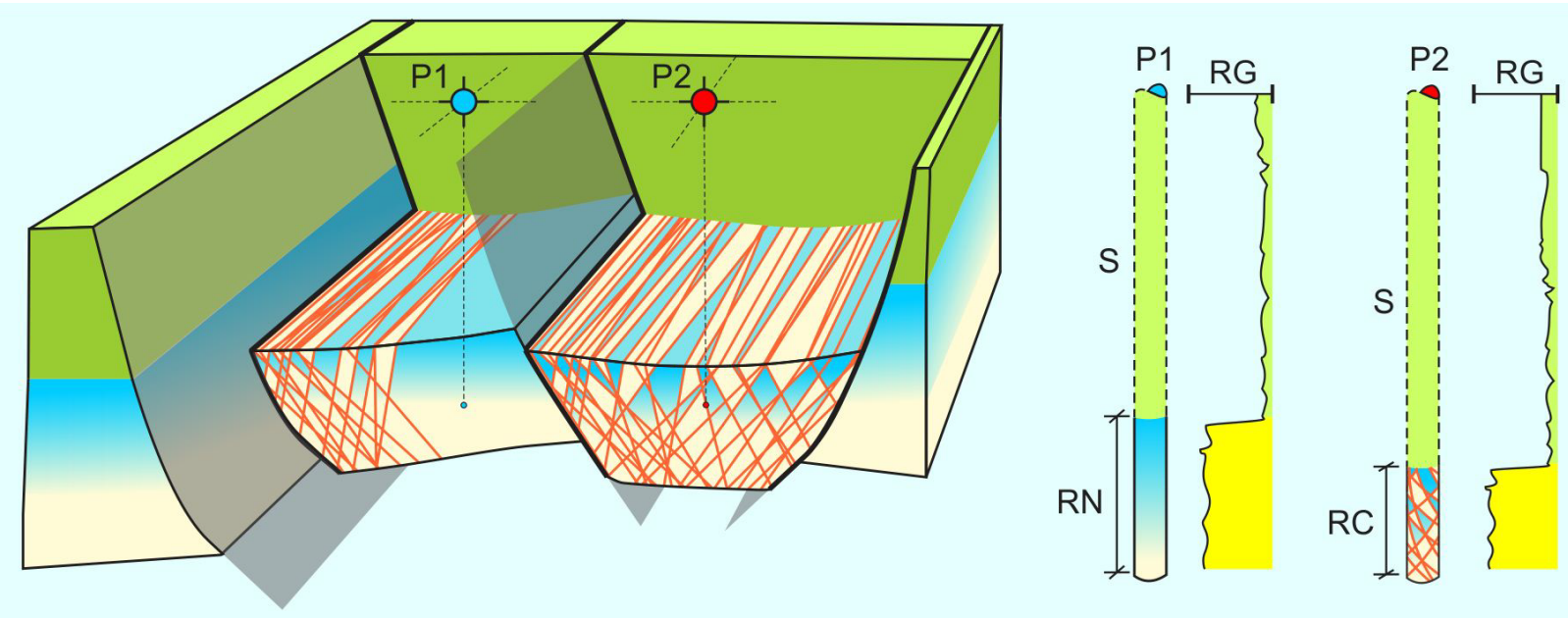

Figura 11. Situação hipotética ilustrando zona de dano de falha em sequências siliciclásticas com potencial para armazenamento de fluidos; nesse contexto, o sistema "reservatório-selante" seria constituído, respectivamente, por arenitos porosos e folhelhos impermeáveis. O primeiro poço (P1) intercepta, abaixo da camada selante (S), o reservatório normal $(\mathrm{RN})$, enquanto o P2, abaixo da mesma camada $\mathrm{S}$, atinge o reservatório cuja porosidade/permeabilidade é controlada por enxames de bandas de deformação (RC). É esperado que a vazão/produção dos dois poços seja bem diferente, devido à presença dessas estruturas. Como a situação de P1 seria invisível em levantamentos sísmicos, poderia, de forma equivocada, atribuir-se essa diferença a fatores que não as bandas de deformação. O perfil de raios gama (RG), ao lado do perfil de poço, é esquemático e ilustra que, provavelmente, este não detectaria as bandas de deformação, uma vez que apresentam a mesma composição mineralógica da rocha hospedeira (arenito poroso). Essa situação elucida a compartimentação de reservatórios por bandas de deformação, o que traria implicação na extração/ recuperação de hidrocarboneto. 
estruturas a falhas com cinemática normal ou transcorrente. A análise dos critérios reológicos, no caso o grau de cataclase, revelou que os arenitos estudados foram submetidos à deformação quando estavam em avançado estágio de litificação. Tal fato é sugerido pelo grau de cataclase (quantidade de matriz cataclástica) observado nas bandas de deformação analisadas, o qual, de modo geral, mostrou-se tendenciosamente mais intenso nas bandas presentes na Formação Maurití do que aquelas inseridas na Formação Abaiara. Entretanto, mais estudos são necessários para afirmar tais distinções com maior segurança.

Portanto, pode-se concluir que o grau de cataclase presente nas bandas de deformação pode estar diretamente relacionado àquele de litificação dos arenitos porosos (durante a deformação), uma vez que a consolidação da rocha a torna cada vez mais coesa, favorecendo o mecanismo de cataclase granular e, consequentemente, desenvolvendo bandas de deformação cataclásticas. Em contraste, arenitos pobremente litificados desenvolveriam, preferencialmente, bandas não cataclásticas (hidroplásticas ou hidrodúcteis). Segundo o comportamento hidrodinâmico dos dois tipos de bandas citados (Figura 12), as cataclásticas tendem a assumir um caráter 'barreira' (devido à matriz cataclástica), enquanto as hidroplásticas teriam característica 'conduto'. Ressaltase que os termos 'conduto' e 'barreira' somente fazem alusão à propriedade ou capacidade das bandas de deformação em não influenciar ou dificultar a passagem/ migração de fluidos, respectivamente. Desse modo, enquanto bandas cataclásticas oferecem resistência natural ao fluxo de fluidos, as hidroplásticas não proporcionam qualquer influência hidrodinâmica a ele.

O estudo geométrico-espacial e cinemático das bandas de deformação permite correlacioná-las aos falhamentos mais importantes da Bacia do Araripe, que são: NE-SW normais, NNE-SSW dextrais e E-W sinistrais. Essa correlação indica que as bandas de deformação estudadas são aproximadamente contemporâneas ao estágio de distensão NWSE, proposto por diversos autores (Françolin e Szatmari, 1987; Sénant e Popoff, 1991; Matos, 1992, 2000; Jardim de Sá et al., 2007; Cardoso et al., 2009) para a evolução do estágio rifte das Bacias Interiores do Nordeste (Figura 13). Desse modo, o estudo meso e microscópico de bandas de deformação pode também fornecer subsídios para a evolução tectonoestrutural das bacias sedimentares.

A determinação do comportamento barreira/conduto das bandas de deformação pode ter papel importante na caracterização de reservatórios. Nesse contexto, visando auxiliar a determinação desse comportamento, o presente estudo sugere, pelo menos, três parâmetros básicos que podem ser relevantes na discriminação do caráter barreira/conduto, independentemente de outros já existentes na literatura: complexidade geométrico-espacial; grau de cataclase e direção com o fluxo de fluidos (Figura 14).

O primeiro parâmetro pode ser observado em afloramentos das zonas de dano de falhas, nas quais quanto maior a complexidade geométrico-espacial das bandas de deformação (espessura, comprimento, rejeito, espaçamento, disposição espacial e densidade de estruturas), mais tortuoso será o caminho dos fluidos por meio delas,

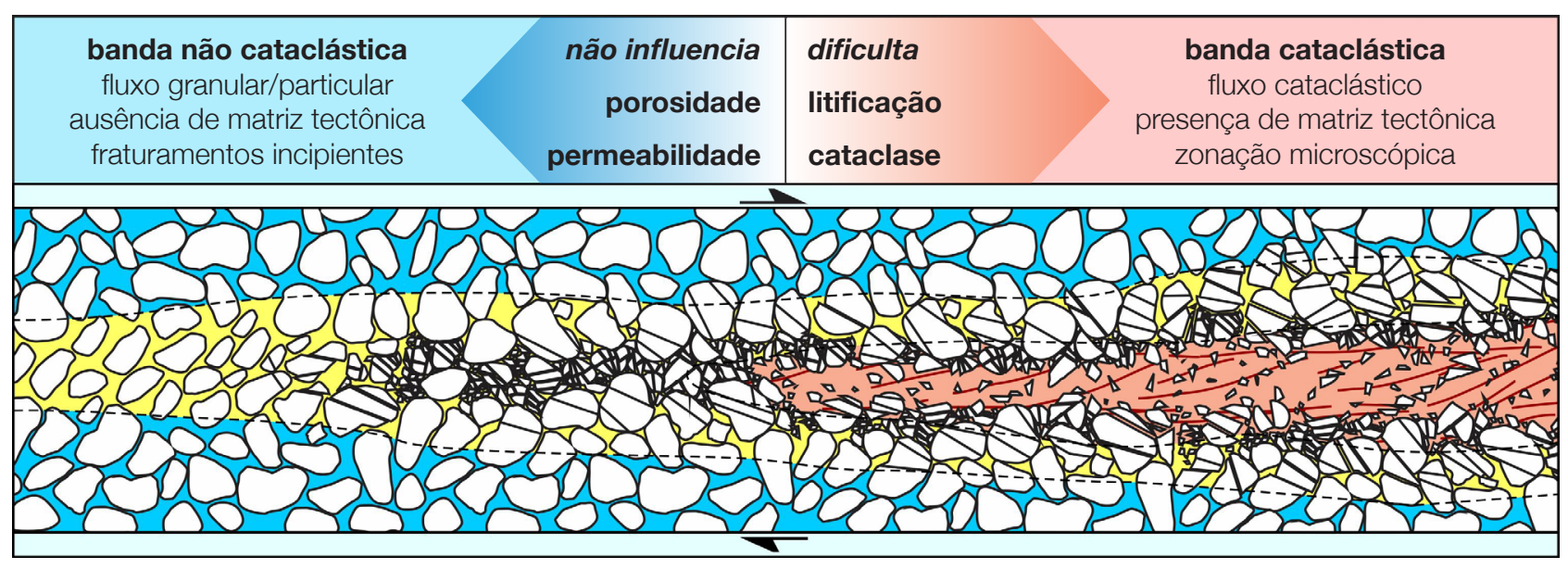

Figura 12. Representação esquemática da relação entre os mecanismos deformacionais atuantes na banda de deformação e o estágio de litificação em que foram desenvolvidas. Arenitos porosos pobremente litificados, submetidos à deformação, produziriam bandas não cataclásticas, enquanto a completa litificação acarretaria o desenvolvimento de bandas cataclásticas. Devido à presença ou ausência de matriz cataclástica, as bandas não cataclásticas não influenciariam a passagem de fluidos, enquanto as cataclásticas dificultariam a mesma. 


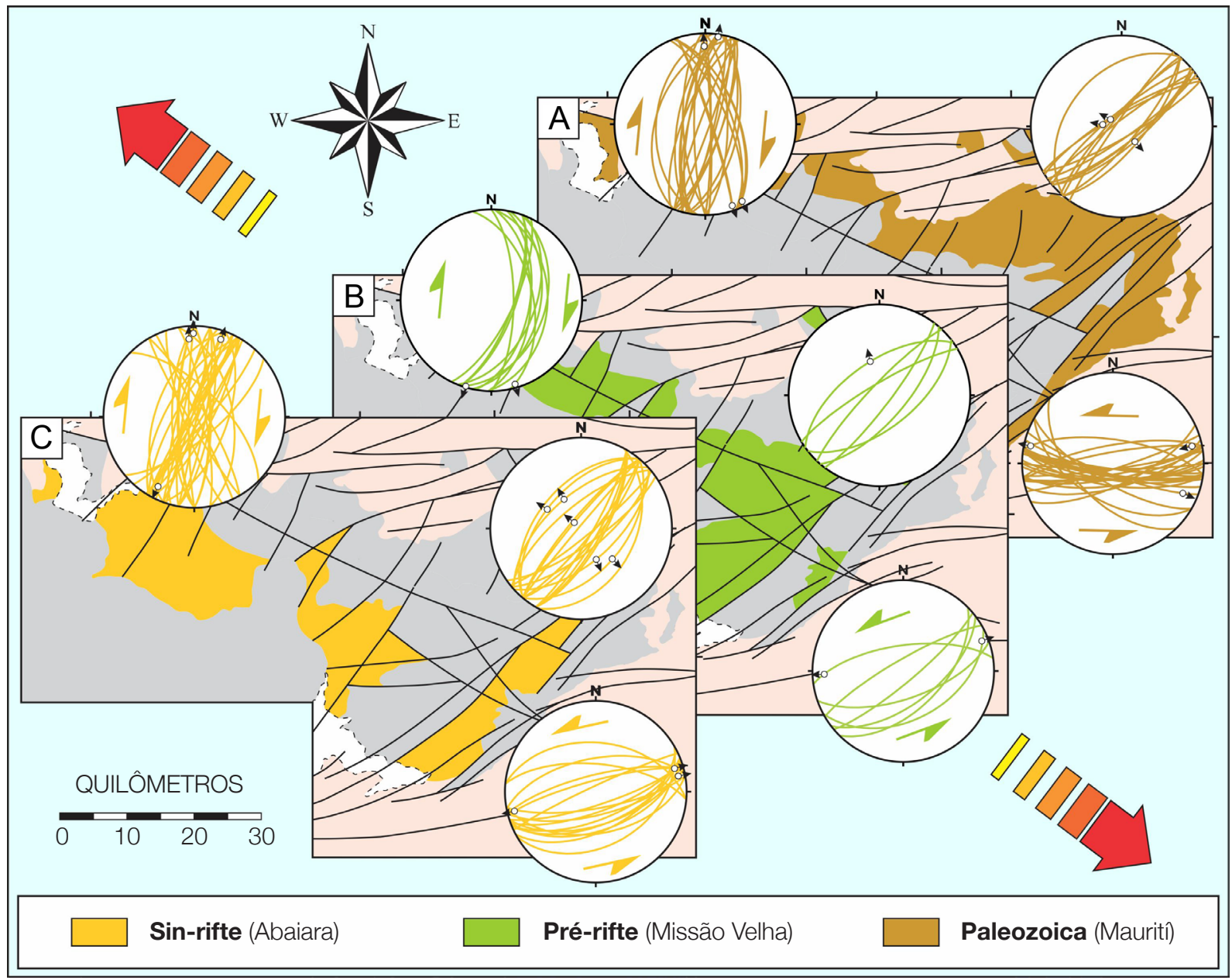

Figura 13. Figura esquemática com as tectonossequências e redes estereográficas para os três conjuntos principais de bandas de deformação da região estudada. Tectonossequências: (A) Paleozoica (Maurití); (B) Pré-rifte (Missão Velha) e (C) Sin-rifte (Abaiara). Cinemática: tendendo a N-S dextral; NE-SW normal; tendendo a E-W sinistral. Esse arranjo cinemático é compatível com um evento tectônico de distensão NW-SE para as bacias interiores do Nordeste brasileiro.

dificultando-se o fluxo de fluidos. O segundo parâmetro é relativo à deformação cataclástica no núcleo da banda de deformação. Pois, quanto maior o grau de cataclase, maior a quantidade de matriz cataclástica, acarretando decréscimo da porosidade, o que atribui um caráter selante à estrutura (Figura 9). O terceiro, e último, parâmetro não foi objeto de pesquisa deste trabalho, porém diversos estudos (Costa et al., 2003; Alves da Silva et al., 2005; Johansen et al., 2005; Fossen e Bale, 2007) mostram que a permeabilidade em direção paralela a estruturas deformacionais tabulares é consideravelmente maior do que aquela em direção perpendicular. Logo, a distribuição espacial das bandas de deformação pode influenciar na direção do fluxo de fluido. Embora esses parâmetros possam ser independentes entre si, o objetivo é tentar observá-los de forma integrada, ou seja, se o comportamento "barreira" for dado pelos três fatores discriminados, o grau de confiabilidade será grande para atribuir o caráter de resistência hidrodinâmica à banda de deformação. Da mesma forma, a atribuição de "não barreira" às bandas de deformação torna-se mais provável se os atributos tiverem o mesmo caráter, ou seja, não influenciarem o fluxo de fluidos.

Por tudo que foi exposto, este estudo reforça a importância de caracterizar as bandas de deformação e seus aspectos geométrico-espaciais e reológicos, tanto para o entendimento da evolução tectônica de uma bacia sedimentar quanto para o reconhecimento de possíveis zonas que interfiram no fluxo de fluidos em rochas reservatórios. Nesse segundo contexto, recomendam-se estudos que integrem análise meso e microscópica de bandas de deformação, métodos geofísicos de poço e testes hidrodinâmicos (porosidade e permeabilidade), com o intuito de tentar identificar e caracterizar intervalos (reservatórios) compartimentados por essas estruturas. 


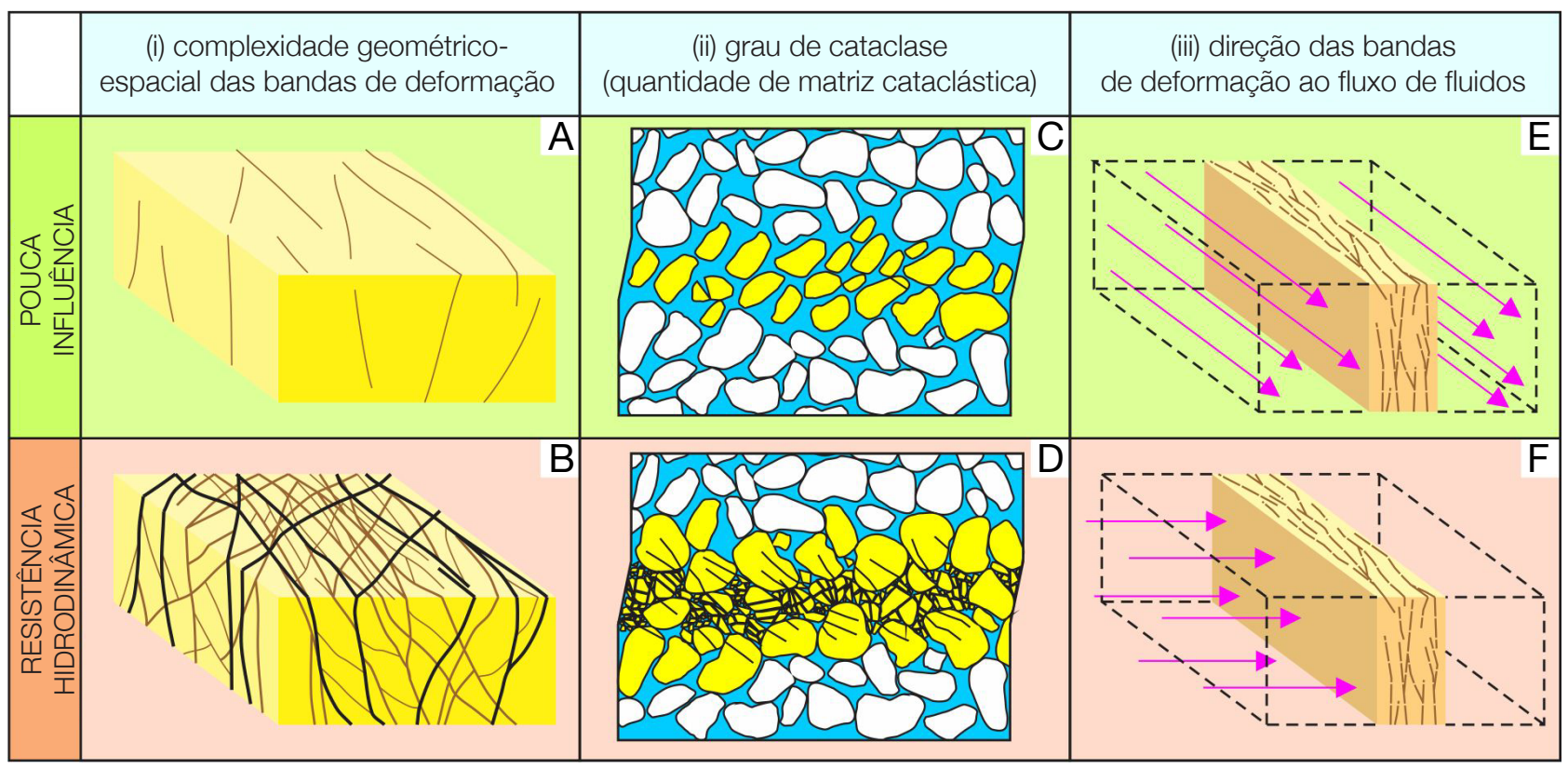

Figura 14. Alguns parâmetros relevantes que podem determinar a influência das bandas de deformação ao fluxo de fluidos. (i) Complexidade geométrico-espacial: (A) baixa complexidade (pouca influência); (B) alta complexidade (resistência hidrodinâmica). (ii) Grau de cataclase é diretamente proporcional à quantidade de matriz cataclástica e inversamente proporcional à porosidade: (C) cataclase incipiente (pouca influência); (D) intensa cataclase (resistência). (iii) Relação entre a direção das bandas de deformação e o fluxo de fluidos: (E) paralela (pouca influência); (F) perpendicular (resistência hidrodinâmica).

\section{AGRADECIMENTOS}

Os autores agradecem à Coordenação de Aperfeiçoamento de Pessoal de Nível Superior (Capes) pela bolsa de Mestrado concedida a JMAN e aos dois revisores anônimos pelos comentários e sugestões.

\section{REFERÊNCIAS}

ALMEIDA, C.;ANTUNES,A.F.;ALVES DASILVA, F.C. Estilos deformacionais nas minas de gesso na bacia do Araripe (NE do Brasil). In: SIMPÓSIO NACIONAL DE ESTUDOS TECTÔNICOS/INTERNATIONAL SYMPOSIUM ON TECTONICS, 12/6, Ouro Preto. Boletim de Resumos... Ouro Preto: SBG, v. 1, p. 81, 2009.

ALVES DA SILVA, F. C.; JARDIM DE SÁ, E. F.; MIRANDA, H. C. B.; MEDEIROS, W. E.; NASCIMENTO, A.; FERREIRA, T. S.; COSTA, P. R. C. What is the real role played by deformation bands in porous sandstones during fluid flow? Insights from the Tucano basin, NE Brazil. In: SIMPÓSIO NACIONAL DE ESTUDOS TECTÔNICOS/INTERNATIONAL
SYMPOSIUM ON TECTONICS, 11/5., 2007, Natal. Boletim de Resumos... Natal: SBG, v. 1, p. 320, 2007.

ALVES DA SILVA, F. C.; FERREIRA, T. S.; COSTA, P. R. C.; GUEDES, I. M.; JARDIM DE SÁ, E. F. Aspectos microestruturais, geométricos e mecanismos de deformação de bandas de deformação e fraturas em arenitos porosos da Bacia de Tucano (BA): Influência na circulação de fluidos. In: SIMPÓSIO DE GEOLOGIA DO NORDESTE, 21, Recife. Boletim de Resumos... Recife: SBG, v. 19, p. 194-198, 2005.

ANTONELLINI, M.; AYDIN, A. Effect of faulting on fluid flow in porous sandstones: geometry and spatial distribution. American Association of Petroleum Geologists Bulletin, v. 79, p. 642-671, 1995.

ANTONELLINI, M.; AYDIN, A. Effect of faulting on fluid flow in porous sandstones: petrophysical properties. American Association of Petroleum Geologists Bulletin, v. 78, p. 355-377, 1994.

ANTONELlini, M. A.; POLlARD, D. D. Distinct element modeling of deformation bands in sandstone. Journal of Structural Geology, v. 17, p. 1165-1182, 1995. 
ANTONELlinI, M. A.; AYDIN, A.; POLlARD, D. D. Microstructure of deformation bands in porous sandstones at Arches National Park, Utah. Journal of Structural Geology, v. 16, p. 941-959, 1994.

AQUINO, M. M. A Formação Abaiara e o arcabouço tectonoestratigráfico da região de Abaiara-Brejo Santo, Bacia do Araripe, NE do Brasil. Monografia (Graduação) - Departamento de Geologia, Universidade Federal do Rio Grande do Norte, Natal, 2009.

ARAÚJO NETTO, J. M. Análise meso e microscópica de bandas de deformação na Bacia do Araripe, Nordeste do Brasil. Monografia (Graduação) - Departamento de Geologia, Universidade Federal do Rio Grande do Norte, Natal, 2009.

ARAÚJO NETTO, J. M.; ALVES DA SILVA, F. C. Bandas de deformação cisalhantes paralelas ao acamamento sedimentar: o exemplo na Bacia do Araripe, Nordeste do Brasil. In: SIMPÓSIO NACIONAL DE ESTUDOS TECTÔNICOS/INTERNATIONAL SYMPOSIUM ON TECTONICS, 13/7. Campinas. Resumos eletrônicos... Campinas: SBG, 2011, 1 CD-ROM.

ARAÚJO NETTO, J. M.; ALVES DA SILVA, F. C. Análise meso e microscópica de bandas de deformação na Formação Maurití, Bacia do Araripe, NE do Brasil. In: SIMPÓSIO DE GEOLOGIA DO NORDESTE, 23. Fortaleza. Resumos eletrônicos... Fortaleza: SBG, 2009, 1 CD-ROM.

ASSINE, M. L. Bacia do Araripe. Boletim de Geociências da Petrobras, v. 15, p. 371-389, 2007.

ASSINE, M. L. Análise estratigráfica da Bacia do Araripe. Nordeste do Brasil. Revista Brasileira de Geociências, v. 22, p. 289-300, 1992.

AYDIN, A. Small faults formed as deformation bands in sandstone. Pure and Applied Geophysics, v. 116, p. 913930, 1978.

AYDIN, A.; BORJA, R. I.; EICHHUBL, P. Geological and mathematical framework for failure modes in granular rock. Journal of Structural Geology, v. 28, p. 83-98, 2006.

CAINE, J. S.; EVANS, J. P.; FOSTER, C. B. Fault zone architecture and permeability structure. Geology, v. 24, p. 1025-1028, 1996.

CARDOSO, F. M. C. O Graben de Palestina: contribuição à estratigrafia e estrutura do estágio rifte da Bacia do Araripe,
Nordeste do Brasil. Dissertação (Mestrado) - Programa de Pós-Graduação em Geodinâmica e Geofísica, Universidade Federal do Rio Grande do Norte, Natal, 2010.

CARDOSO, F. M. C.; JARDIM DE SÁ, E. F.; ALVES DA SILVA, F. C.; SCHERER, C. M. S. O Graben Serrote das Cacimbas-Palestina (Sub-bacia Cariri - Bacia do Araripe, NE do Brasil): Geometria e estilo estrutural. In: SIMPÓSIO DE GEOLOGIA DO NORDESTE, 23. Fortaleza. Resumos eletrônicos... Fortaleza: SBG, 2009, 1 CD-ROM.

CELLO, G.; TONDI, E.; MICARELLI, L.; INVERNIZZI, C. Fault zone fabrics and geofluid properties as indicators of rock deformation modes. Journal of Geodynamics, v. 32, p. 543-565, 2001.

COSTA, A. B. S. Diagênese e proveniência dos arenitos da tectonossequência Rifte na bacia do Rio do Peixe Araripe, NE do Brasil. Dissertação (Mestrado) - Programa de PósGraduação em Geodinâmica e Geofísica, Universidade Federal do Rio Grande do Norte, Natal, 2010.

COSTA, P. R. C.; JARDIM DE SÁ, E. F.; GUEDES I. M. G., ALVES DA SILVA, F. C. Caracterização estrutural da área da Serra do Letreiro, oeste da cidade de Jeremoabo (NE da Bahia). Revista de Geologia, v. 16, p. 49-60, 2003.

DRAGANITS, E.; GRASEMANN, B.; HAGER, C. Conjugate deformation band faults in the Lower Devonian Muth Formation (Tethyan Zone, NW India): evidence for pre-Himalayan deformation structures. Geological Magazine, v. 142, p. 765-781, 2005.

FAULKNER, D. R; JACKSON, C. A. L.; LUNNR, J.; SCHLISCHE, R. W.; SHIPTON, Z. K.; WIBBERLEY, C. A. J. A review of recent developments concerning the structure, mechanics and fluid flow of fault zones. Journal of Structural Geology, v. 32, p. 1557-1575, 2010.

FOSSEN, H.; BALE, A. Deformation bands and their influence on fluid flow. American Association of Petroleum Geologists Bulletin, v. 91, p. 1685-1700, 2007.

FOSSEN, H.; SCHULTZ, R. A.; SHIPTON, Z. K.; MAIR, K. Deformation bands in sandstones: a review. Journal of the Geological Society, v. 164, p. 755-769, 2007.

FRANÇOLIN, J. B. L.; SZATMARI, P. Mecanismo de rifteamento da porção oriental da margem brasileira. Revista Brasileira de Geociências, v. 17, p. 196-207, 1987. 
HESTHAMMER, J.; JOHANSEN, T. E. S.; WATTS, L. Spacial relationship within fault damage zones in sandstone. Marine and Petroleum Geology, v. 17, p. 873-893, 2000.

HOLCOMB, D.; RUDNICKI, J. W.; ISSEN, K. A.; STERNLOF, K. Compaction localization in the Earth and the laboratory: state of the research and research directions. Acta Geotechnica, v. 2, p. 1-15, 2007.

JARDIM DE SÁ, E. F.; SOUSA, D. C.; AQUINO, M.M.; SCHERER, C. M. S.; CÓRDOBA, V. C.; ALVES DA SILVA, F. C. A Tectonossequência Rifte da Bacia do Araripe, NE do Brasil. In: SIMPÓSIO DE GEOLOGIA DO NORDESTE, 23. Fortaleza. Resumos eletrônicos... Fortaleza: SBG, 2009, 1 CD-ROM.

JARDIMDESÁ,E. F.; LINS, F.A.P. L.;ALVES DASILVA, F. C.; COSTA, P. R. C.; MEDEIROS, W. E.; SENA, E. S.; ANTUNES, A. F.; SOUSA, D. C.; CÓRDOBA, V. C.; SOUSA, A. A. T.; SANTANA, F. L.; ANDRADE, P. R. O. As Bacias Interiores do Nordeste: integração de dados estruturais e gravimétrico. In: SIMPÓSIO NACIONAL DE ESTUDOS TECTÔNICOS/V INTERNATIONAL SYMPOSIUM ON TECTONICS, 11/5. Boletim de Resumos... Natal: SBG, 2007, v. 1, p. 70.

JOHANSEN, T. E. S.; FOSSEN, H.; KLUGE, R. The impact of syn-faulting porosity reduction on damage zone archtecture in porous sandstone: an outcrop example from the Moab Fault, Utah. Journal of Structural Geology, v. 27, p. 1469-1485, 2005.

KIM, Y. S.; PEACOCK, D. C. P.; SANDERSON, D. J. Fault damage zones. Journal of Structural Geology, v. 26, p. 503-517, 2004.

KIM, Y. S.; PEACOCK, D. C. P.; SANDERSON, D. J. Mesoscale strike-slip faults and damage zones at Marsalforn, Gozo Island, Malta. Journal of Structural Geology, v. 25, p. 793-812, 2003.

MAIR, K.; MAIN, I.; ELPHYCK, S. Sequential growth of deformation bands in laboratory. Journal of Structural Geology, v. 22, p. 25-42, 2000.
MATOS, R. M. D. Tectonic evolution of the Equatorial South Atlantic. In: MOHRIAK, W.; TALWANI, M. Atlantic rifts and continental margins. Geophysical Monograph, v. 115, p. 331-354, 2000.

MATOS, R. M. D. The Northeast Brazilian Rift System. Tectonics, v. 11, p. 766-791, 1992.

MEDEIROS, W. E.; DO NASCIMENTO, A. F.; ALVES DA SILVA, F. C.; DESTRO, N.; DEMÉTRIO, J. G. A. Evidence of hydraulic connectivity across deformation bands from field pumping tests: Two examples from Tucano Basin, NE Brazil. Journal of Structural Geology, v. 32, p. 1783-1791, 2010.

MELO, T. V. N.; ALVES DA SILVA, F. C. Contribuição à geologia das Bacias Interiores da Zona Transversal (Betânia, Mirandiba e São José do Belmonte) do NE do Brasil. In: SIMPÓSIO DE GEOLOGIA DO NORDESTE, 23. Fortaleza. Resumos eletrônicos... Fortaleza: SBG, 2009, 1 CD-ROM.

MENÉNDEZ, B.; ZHU, W.; WONG, T. F. Micromechanics of brittle faulting and cataclastic flow in Berea sandstone. Journal of Structural Geology, v. 18, p. 1-16, 1996.

MOLLEMA, P. N.; ANTONELLINI, M. A. Compaction bands: a structural analog for anti-mode I cracks in aeolian sandstone. Tectonophysics, v. 267, p. 209-228, 1996.

PONTE, F. C.; APPI, C. J. Proposta de revisão da coluna litoestratigráfica da Bacia do Araripe. In: CONGRESSO BRASILEIRO DE GEOLOGIA, 36. Natal. Boletim de Resumos... Natal: SBG, v. 1, p. 211-226, 1990.

SÉNANT, J.; POPOFF, M. Early Cretaceous Extension in Northeast Brazil related to the South Atlantic opening. Tectonophysics, v. 198, p. 35-46, 1991.

SHIPTON, K. Z.; COWIE, P. A. A conceptual model for the origin of fault damage zone structures in high-porosity sandstone. Journal of Structural Geology, v. 25, p. 333344, 2003. 